\title{
DEVELOPMENT OF A GENERIC ACTIVITIES MODEL OF COMMAND AND CONTROL
}

\author{
N. A. Stanton, C. Baber ${ }^{1}$, G. H. Walker, R. J. Houghton ${ }^{1}$, R. McMaster ${ }^{1}$, R. \\ Stewart $^{2}$, D. Harris ${ }^{2}$, D. Jenkins, M. S. Young and P. M. Salmon. \\ Defence Technology Centre for Human factors Integration (DTC-HFI) \\ Ergonomics Research Group, BITlab, School of Engineering and Design, Brunel \\ University, Uxbridge, Middlesex, UB8 3PH, UK \\ ${ }^{1}$ School of Electronic, Electrical and Computer Engineering, University of \\ Birmingham, Edgbaston, Birmingham, B15 2TT, UK \\ ${ }^{2}$ Department of Human Factors, School of Engineering, Cranfield University \\ Cranfield, Bedfordshire, MK43 0AL, UK
}

\begin{abstract}
This paper reports on five different models of command and control. Four different models are reviewed: a process model, a contextual control model, a decision ladder model and a functional model. Further to this, command and control activities are analysed in three distinct domains: armed forces, emergency services and civilian services. From this analysis, taxonomies of command and control activities are developed that give rise to an activities model of command and control. This model will be used to guide further research into technological support of command and control activities.
\end{abstract}

Keywords: command and control, models, taxonomy, activities

Contact: neville.stanton@brunel.ac.uk

Running header: Activities model of command and control

\section{Four models of command and control}

The purpose of this paper is to investigate alternative models of command and control. In particular, the paper presents the development of an activity model and contrasts this with control, contextual, decision and functional models that have been proposed by other researchers. The purpose of the activity model is to provide a research tool that may be applied to any command and control domain. It is claimed that this model will enable researchers to conduct investigations into different aspects of command and control in a systematic manner. The main aims of any model are to simplify complexity and to provide the basis for predictions of performance of the phenomena under consideration. 
Four contemporary models of command and control are presented as a way of summing up the field. The first is a control theoretic model by Lawson (1981), the second is a control modes model by Hollnagel (1993), the third is the decision ladder model by Rasmussen (1974) and Vicente (1999), and the fourth is a functional command and control model by Smalley (2003). As there is approximately a decade between the publications of these models, they are probably representative of the changes in thinking over the past three decades, although each model only represents a snapshot of each particular approach.

Command and control may be viewed as an information processing chain, as data flows between the environment, one's own forces and the command centre. The model in Figure One epitomises this perspective. The model is rooted in the idea that there is some desired state that the command centre seeks to achieve. Data are extracted from the environment and processed. The understanding of these data are then compared with the desired state. If there is any discrepancy between the desired state and the current state, the command centre has to make decisions about how to bring about the desired state. These decisions are turned into a set of actions, which are then communicated to their own forces. The data extraction cycle then begins afresh.

\section{FIGURE ONE ABOUT HERE PLEASE}

Figure 1. An adapted version of Lawson's model of the command and control process. From: Lawson, J. S. (1981) Command and control as a process. IEEE Control Systems Magazine, March, 86-93.

Lawson's model owes much to the ideas from control theory. The comparison of actual and desired states implies a feedback process and some form of regulation. Central to his model, therefore, would be the "compare” function. The feedback involves control of "own forces" to affect a change to the environment. The notional "actual” and "desired” states imply phenomena that can be described in terms of quantitative, discrete data; in other words it is not easy to see how the model would cope if the actual state was highly uncertain. Nor is it easy to see what would happen if the changes to the environment led to consequences which lay outside the limits defined by the discrete state. The model does indicate the central issue that command 
can be thought of as working towards some specified effect or intent but suffers, however, from its apparent reliance on a deterministic sequence of activities in response to discrete events.

Hollnagel (1993) developed a Contextual Control approach to human behaviour, based on cognitive modes, to explain the effects of the context in which people performed their actions. Rather than command and control being a pre-determined sequence of events, Hollnagel has argued that it is a constructive operation where the operator actively decides which action to take according to the context of the situation together with his/her own level of competence. Although set patterns of behaviour maybe observed, Hollnagel points out that this is reflective of both the environment as well as the cognitive goal of the person, both of which contain variability. In the Contextual Control Model, shown in figure two, four proposed modes of control are as follows.

- Strategic Control - is defined as the 'global view', where the operator concentrates on long term planning and higher level goals.

- Tactical Control - is more characteristic of a pre-planned action, where the operator will use known rules and procedures to plan and carry out short term actions.

- Opportunistic Control - is characterised by a chance action taken due to time, constraints and again lack of knowledge or expertise and an abnormal environmental state.

- Scrambled Control - is characterised by a completely unpredictable situation where the operator has no control and has to act in an unplanned manner, as a matter of urgency.

\section{FIGURE TWO ABOUT HERE PLEASE}

Figure 2. Hollnagel's contextual control model. From: Hollnagel, E. (1993). Human reliability analysis: Context and control. London: Academic Press.

The degree of control is, therefore, determined by a number of varying interdependent factors. Hollnagel considers that availability of subjective time is a main function of command and control - this means that as the operator perceives more time available 
so s/he gains more control of the task/situation. The factors affecting the perception of available time may include: the number of goals, the availability of plans to meet these goals, the modes of execution of those plans and the time available. At any point in time the system operator is attempting to optimise all of these criteria. Hollnagel's model differs from Lawson's, in that it does not prescribe the sequence and relations of command and control activities; rather it proposes contextual differences in the control mode. There is some evidence to support this hypothesis. In a study of team behaviour in a supervisory control task, Stanton et al (2001) showed that the transitions between control modes were consistent with Hollnagel's model.

The Decision Ladder model of activity was developed by Rasmussen (1974) who observed that expert users were relying on a mixture of knowledge-based, rule-based and skill-based behaviour to conduct tasks. Rasmussen proposed that the sequence of steps between the initiating cue and the final manipulation of the system can be identified as the steps a novice must necessarily take to carry out the sub task, as shown in figure three. Studies of expert performance may then result in a description of his performance in terms of shunting leaps with this basic sequence. The ladder can be seen to contain two different types of node: information processing activities (represented by the rectangular boxes) and knowledge states (represented by the circles). By folding this list in half it is possible to add links between the two sides. There are two types of shortcut that can be applied to the ladder; 'shunts' connect an information-processing activity to a state of knowledge (box to circle) and 'leaps' connect two states of knowledge (circle to circle). This is where one state of knowledge can be directly related to another without any further information processing. It is not possible to link straight from one box to another, as this misses out the resultant knowledge state (Vicente, 1999).

\section{FIGURE THREE ABOUT HERE PLEASE}

Figure 3. Rasmussen and Vicente’s decision ladder model. From: Rasmussen, J. (1974). The human data processor as a system component: Bits and pieces of a model (Report No. Risø-M-1722). Roskilde, Denmark: Danish Atomic Energy Commission. 
According to Naikar \& Pierce (2003) the left side of the decision ladder represents an actor observing the current system state whereas the right side of the decision ladder represents an agent planning and executing tasks and procedures to achieve a target system state. Sometimes observing information and diagnosing the current system state immediately signals a procedure to execute. This means that rule based shortcuts can be shown in the centre of the ladder. On the other hand the actor may have to engage in effortful, knowledge-based goal evaluation to determine the procedure to execute; this is represented in the top of the ladder. There are two types of shortcut that can be applied to the ladder; 'shunts' connect an informationprocessing activity to a state of knowledge (box to circle) and 'leaps' connect two states of knowledge (circle to circle). The path in which the operator moves through the ladder is dependant on a number of factors including; their workload, experience and familiarity with the current task.

Smalley (2003) proposed a functional model of command and control, comprising some seven operational and decision support functions (six in the ovals and one in the box) and ten information processing activities (appended to the input and output arrows). The ten information processing activities are: primary situation awareness, planning, information exchange, tactical situation reports, current situation awareness, directing plan of execution, system operation, system monitoring, system status, and internal co-ordination and communications. A representation of the relationship between the operation and decision support functions and information processing activities is shown in figure four.

\section{FIGURE FOUR ABOUT HERE PLEASE}

Figure 4. Smalley's functional command and control model. From: Smalley, J. (2003) Cognitive factors in the analysis, design and assessment of command and control systems. In: E. Hollnagel (ed) Handbook of Cognitive Task Design. Mahwah, New Jersey: Lawrence Erlbaum Associates (223-253).

Information about the state of the world is collected through the primary situation awareness activities. The various sources of information are combined so that targets and routes can be defined in the planning activities. Information about targets, routes 
and intentions is exchanged with other forces. The status of the mission is communicated through the tactical situation reports. Current situation awareness activities merge information about the mission with primary situation awareness, to inform the planning process. The information from this latter set of activities will cue the start of the activities that direct the plan of execution. This, in turn, informs activities associated with the direction of system operation. The system is monitored, to see if outcomes are as expected. Any changes in the system status may lead to changes in the planning and the directing of the plan. Internal and external coordination and communication activities keep the command and control system functioning.

Smalley's model comprises an integration of many command and control activities with feed-forward and feed-back loops. It has a higher level of command and control fidelity than the other two models. The model suggests that 'command' activities (at the top of the figure) are separate, but connected to, the 'control' activities (at the bottom of the figure). The activities on the right-hand side of the figure are concerned with internal operation of the system, whereas the activities on the left-hand side of the figure are concerned with interfacing with the external environment. In contrast to the other three models, Smalley’s model offers high much higher fidelity for command and control.

As stated previously, the purpose of a generic model of command and control is to reduce complexity, and offer outcome metrics that can detect and describe nonrandom emergent properties. Emergent properties exist where the "characteristics of the whole are developed (emerge) from the interactions of their components in a nonapparent way” (Bar Yam, 1997). The optimal generic model of command and control can therefore be defined as one that is sensitive enough to detect emergent properties, whilst containing merely 'sufficient' complexity to explain (and predict) these "widely observed properties and behaviours in terms of more fundamental, or deeper, concepts” (Wainwright \& Mulligan, 2004; Builder, Bankes \& Nordin, 1999).

The product of combining command (authority) with control (the means to assert this authority) are the emergent properties of "unity of effort in the accomplishment of a [common goal]” (Jones, 1993) and “decision superiority” (DoD, 1999p. 28). Despite 
the militaristic undertones, the notion of command and control is generic and not specific to a particular domain. An analysis of three distinctly different domains for command and control was undertaken in the following section of the paper.

\section{Three Domains for Command and Control}

The three domains selected for analysis of command and control in our studies were the emergency services (i.e., Police and Fire Service - McMaster et al, 2005; see also Houghton et al., in press), civilian services (i.e., National Grid, National Air Traffic Services, and Network Rail - Walker et al, 2006) and armed services (Airforce E3D, Navy type 23 frigate and Army CAST brigade level exercise - Stanton et al, 2005). It is the cumulative understanding of Command and Control, developed through a variety of domains, which led to the development of a generic model.

\subsection{Emergency Services}

Two command and control application areas were analysed in the emergency services: the fire service and the police.

In the UK (and several other countries across Europe), the emergency services operate a tripartite control structure. Major incidents, which require high-level command are termed Gold. Typically, these occur when the coordination of a great many units is required. Usually such command is not required and command can be exercised on a local, tactical level, which characterises Bronze command. Between Gold and Bronze, lies a strategic command level termed Silver.

In order to study fire operations, observations were conducted at the Fire Service College. The training college provided access to command structures for ecologically valid exercises, without the potential risk associated with actual fires. During each exercise, an incident commander (the Assistant Divisional Officer or ADO) issues commands to the sectors being controlled. For a medium-to-large incident, within the Silver command level it is necessary to divide response into sectors, which can be either geographical (i.e., parts of the fire ground), or functional (for example, managing water supplies or a breath-apparatus crew). The exercises that were observed covered operations including the search for a hazardous chemical, fire in a chemical plant, and a road traffic accident. 
Police operations were studied through observations in Force Command and Control (FCC) and Operational Command Unit (OCU) sites. The focus was on accidents requiring immediate response, that is, where suspects were on the premises or an incident was in progress. In carrying out their duties, West Midlands Police (WMP) can cover a wide variety of incidents, ranging from assaults and robberies, to burglaries and road traffic accidents. FCC Emergency Call Operators prioritise incidents as requiring immediate, early or routine response, according to their urgency. Incidents that are graded as “Immediate Response” are those that require an urgent Police presence, usually because there is a high risk of serious injury or death, or where there is a good chance of an arrest if the response is rapid (i.e. when the crime is still taking place). When an incident is prioritised "Immediate Response", only the bare minimum of details are taken from the caller by the Emergency Call Operator (i.e. location, nature of emergency and caller's name), which are then passed on to the OCU responsible for the area where the call originated. The Operations Centre within the OCU in question will then review the incident priority and allocate resources to respond to it. In the case of "Immediate Response” incidents, WMP are required to attend the scene within 10 minutes.

\subsection{Civilian Services}

Thee command and control applications areas were analysed in the civilian services: air traffic control, the rail network and the national electricity grid.

Air Traffic Control is a highly evolved process based on clearly defined procedures. The procedures used in normal operations are based on the aircraft flight plan, which describes its intended route. This route includes the starting location, beacons or reporting points that it will pass and its final destination airport. This information derives from the flight data strip computer, and is presented to the controllers in the form of a flight progress strip by flight strip assistants. The flight data strip contains coded information showing particulars about the aircraft and its route. From this information the controller can determine the approximate time and position at which the aircraft will arrive in the sector. The UK controlled airspace is divided into sectors, each of which is monitored by an air traffic control team. As an aircraft travels through these sectors, responsibility for controlling it transfers from one 
ATCO to another. Making sure that aircraft pass through this airspace and take off and land safely is the key responsibility of ATCOs.

Three scenarios were analysed in the UK rail industry. The activities under consideration were those involved in the setting up of safety systems required when carrying out maintenance of track. Under normal conditions a signaller has the key responsibility for controlling train movements and maintaining safety for an area of railway line. This control occurs remote from the line at a control centre (a signalbox or signalling centre). These can be located many miles from where activity could be taking place. During maintenance, another person takes responsibility (possession) for an area of the line. Communication and coordination is required to transfer responsibility between the signaller and track maintenance engineers. The track maintenance engineers also have to communicate and coordinate with various other personnel, such as those carrying out maintenance within their areas of control, drivers of trains and on track-plant which may be in the zone where maintenance is taking place (called the possession), and personnel implementing aspects of the possession (all of which may also be dispersed over a certain geographical area). Three specific maintenance scenarios analysed were: planned maintenance (the processes and activities for setting up a possession for a stretch of track so that planned maintenance can take place), emergency engineering work (the processes and activities for unplanned emergency engineering work on the line, such as when track or infrastructure has been damaged or has suddenly degraded) and ending track possession (the reversal of the processes and activities for planned maintenance).

National Grid Transco own, maintain and operate the high voltage electricity transmission system in England and Wales. This complex and distributed system is comprised of 4500 miles of overhead lines, 410 miles of underground cables and 341 substations. The scenarios under analysis were observed at the Network Operations Centre (NOC) control room and in a number of geographically remote substations. There were three main parties involved in an outage scenario, a party working at Substation A on the Substation B circuit, a party working at Substation B on the Substation A circuit (i.e., at either end of a 30 mile overhead line) and an overhead line party working in between the two Substations. A return to service scenario was also observed. The scenario also involved a circuit between substations and the 
National Grid Transco Network Operations Centre. The scenario under analysis involved the return from isolation of the circuit where the observation focussed upon six main parties that were involved and the complex technological infrastructure that facilitated remote operations and communication.

\subsection{Armed Services}

All three armed services were analysed for command and control applications: army. air-force and navy.

The study of command and control in the Army took place at the Command And Staff Training (CAST) exercises at the British Army's Land Warfare Centre in Warminster Observations of both Brigade Headquarters and Battle Group Headquarters were undertaken. The studies were focused on the planning process, known as the Combat Estimate, war-gaming and simulation of the enactment of the plan. The plan is considered adequate when it meets the commander's intent, provides clear guidance to all sub-units and enough detail to allow the effects of the available combat power to be synchronised at critical points (Command and Staff Procedures, 2005). Flexibility is described in terms of the agility and versatility required to respond to the situation (and enemy) as events occur. Timeliness, finally, is about ensuring that there is 'sufficient' time for the battle procedure to be enacted. The Combat Estimate is summed up (and often referred to) as the seven questions. These questions break down the process by which plans are made and actions taken; they summarise the activities and outcomes of the different stages of the process.

The scenario analysed in the RAF took place on board an E3D AWACS (Airborne Warning and Control System) aircraft and covers the operations for a simulated war exercise. For more information, see Stewart et al (this volume).

The Royal Navy allowed a team of researchers access to one of their training establishments - the Maritime Warfare School - on HMS Dryad in Southwick, Hampshire. Observations were made during Command Team Training (CTT). This programme involved training the Command Team of a warship in the skills which would be necessary for them to defend their ship in a multi-threat environment, "assimilate, interpret and respond correctly to the information received from external 
sources while reporting, directing and managing their and other units in the joint conduct of maritime operations” (Hoyle, 2001,p3). The training programme was conducted in a representative Type 23 Ship 'Operations Room Simulator' (ORS). The simulator room is slightly enlarged to allow for staff observation but otherwise was to scale (Hoyle, 2001). In addition to this simulator room there was a room which included a team of personnel who helped make any threats seem more realistic, i.e. they portrayed other ships and aircraft as well as personnel from other parts of the ship. Three scenarios (air threat, subsurface threat and surface threat) were observed for this report. The Anti-Air Warfare Officer (AAWO) was the main agent observed in the air threat scenario and the (Principal Warfare Officer) PWO was the main agent observed for the subsurface and surface threat scenarios. Other agents were heard and seen interacting with either the AAWO or the PWO.

\subsection{Common features of the domains and application of command and control}

Despite the differences in the domains, the command and control applications share many common features. First, they are typified by the presence of a central, remote, control room. Data from the field are sent to displays and/or paper records about the events as they unfold over time. Second, there is (currently) considerable reliance on the transmission of verbal messages between the field and the central control room. These messages are used to transmit report and command instructions. Third, a good deal of the planning activities occurs in the central control room, which are then transmitted to the field. There are collaborative discussions between the central control room and agents in the field on changes to the plan in light of particular circumstances found in-situ. Finally, the activities tend to be a mixture of proactive command instructions and reactive control measures. It is hypothesised that one of the determinants of the success or failure of a command and control systems will be the degree to which both the remote control centre and agents in-the field can achieve shared situational understanding about factors such as: reports of events in the field, command intent, plans, risks, resource capability, and instructions. This places a heavy reliance on the effectiveness of the communications and media between the various parties in the command and control system.

\section{Development of a Generic Task Model of Command and Control}


Analysis of the task analyses from these three domains led to the development of a taxonomy of command and control activities, as indicated in table one. The resultant data from the observational studies and task analyses were subject to content analysis, in order to pick out clusters of activities. These clusters were subjected to thematic analysis consistent with a 'grounded theory' approach to data-driven research. It was possible to allocate most of the tasks in the task analysis to one of these categories. To this extent, the building of a generic model of command and control was driven by the data from the observations and task analyses.

Table 1. Taxonomy of command and control activities

\section{TABLE ONE ABOUT HERE PLEASE}

The detailed taxonomies may be found in the following seven tables, numbered two to eight. The 'receive' taxonomy, as shown in table two, identifies activities that are associated with receiving orders, requests, data and information that relate to past, present or future events. This information can act as a trigger for new command and control tasks, or modifications of ongoing tasks. Thus the information may be either feed-forward or feedback.

Table 2. The 'receive' activities taxonomy

\section{TABLE TWO ABOUT HERE PLEASE}

The 'planning' taxonomy, as shown in table three, describes all of the activities associated with the preparation, assessment and choice of the plan. These activities include gathering of information, assessing options, discussing effects and prioritising alternative courses of action.

Table 3. The 'planning' activities taxonomy

\section{TABLE THREE ABOUT HERE PLEASE}

The 'rehearsal' taxonomy, as shown in table four, identifies activities that are associated with rehearsal of the plan prior to implementation. Most of the domains discuss the plan with the other parties, with the exception of ATC. The army also run a war-game on a map to consider the synchronisation of potential effects and likely courses of enemy responses. 
Table 4. The 'rehearsal' activities taxonomy

\section{TABLE FOUR ABOUT HERE PLEASE}

The 'communicate' taxonomy, as shown in table five, refers to all of the activities associated with remote communication from the control centre. When the plan is communicated verbally, there is a read-out and read-back procedure, which may also act as a verbal rehearsal, although it does not formally belong in the 'rehearsal' taxonomy.

Table 5. The ‘communicate’ activities taxonomy

\section{TABLE FIVE ABOUT HERE PLEASE}

The 'request' taxonomy, as shown in table six, refers to manner in which the command and control centre asks for information and support from other parties. This includes agents in the field, other agencies, and other personnel in the command centre.

Table 6. The 'request' activities taxonomy

\section{TABLE SIX ABOUT HERE PLEASE}

The 'monitor' taxonomy, as shown in table seven, refers to all of the activities associated with keeping track of the changing situation and events being performed remotely. These activities include recording any changes to the plan as they occur.

Table 7. The 'monitor' activities taxonomy

\section{TABLE SEVEN ABOUT HERE PLEASE}

The 'review' taxonomy, as shown in table eight, refers to all of the activities associated with an after-action review of the successful and less successful aspects of the activities. This includes formal procedures, informal records, incident reports, and accident tribunals. The armed forces tend to be very thorough in applying this analysis at the end of every engagement, whereas the civilian and emergency services tend to be more informal unless there is an accident or near miss.

Table 8. The 'review' activities taxonomy 


\section{TABLE EIGHT ABOUT HERE PLEASE}

From the taxonomies, and an analysis of the previous command and control models, it was possible to develop a generic process model, as shown in figure five.

Construction of the model was driven by the data collected through observation from the different domains, and the subsequent thematic analysis and taxonomic development. In the tradition of 'grounded theory' the generic command and control model was as a result of our observations, rather than an attempt to impose any preconceived ideas of command and control. This may account for many of the differences in the current model developed in the course of the current research and those that have come before it.

It is proposed that the command and control activities are triggered by events at the top of the figure, such as the receipt of orders of information, which provide a mission and a description of current situation of events in the field. The gap between the mission and the current situation lead the command system to determine the effects that will narrow that gap. This in turn requires the analysis of resources and constraints in the given situations. From these activities plans are developed, evaluated and selected. The chosen plans are then rehearsed before being communicated to agents in the field. As the plan in enacted, feedback from the field is sought to check that events are unfolding as expected. Changes to the mission or the events in the field may require the plan to be updated or revised. When the mission has achieved the required effects, the current set of command and control activities may come to an end.

The model in figure five distinguishes between 'command' activities, in the shaded triangle on the left-hand side of the figure, and 'control' activities, in the shaded triangle on the right-hand side of the figure. Command comprises proactive, missiondriven, planning and co-ordination activities. Control comprises reactive, eventdriven, monitoring and communication activities. The former implies the transfer of mission intent whereas the latter implies reaction to specific situations.

\section{FIGURE FIVE ABOUT HERE PLEASE}

Figure 5. Generic process model of command and control. 
As the process model is derived from the analysis of the three different domains, it should also explain the activities that go on in each of them.

In the military domain, such as the army, the scenario begins with orders from a higher level in the command chain. These orders form the mission that has to be turned into a plan. The plan starts as an outline of the required effects on a map. These effects have to be turned into alternative courses of action that would result in the required effects, taking any intelligence of what the enemy is doing into account. Each of the courses of action is evaluated in terms of the resources required and possible risks. The most optimal plan is selected, although alternative courses of action are kept in reserve. The plan is rehearsed though a war gaming exercise and then communicated to the assets in the field, who might have to undertake lower level planning to meet their mission. If all levels of the organisation are content with the plan then it is put into action. Regular field reports are requested and the effects of the changing situation are fed-back to check if events are unfolding as anticipated. Deviations from planned events may require more planning to determine if changes in the course of action are required. Changes in the plan are fed-up and down the command chain. When the mission objectives have been achieved, the scenario ends.

In the emergency services domain, such as the fire service, the scenario begins with an emergency call from a member of the public, or from another emergency service. As much information as possible about the event it recorded, so that preliminary planning may be undertaken. Templates plans for different types of event can be applied, such as 'Domestic House Fire', 'Road Traffic Accident, and 'Chemical Tanker Spillage'. This can operate as a means of guiding the initial responses to the emergency, and getting the right kind of vehicles, equipment and people to the event. If the event turns out to be as expected, much of the incident planning can be left to the field operative, such as determining the appropriate course of action and implementing the plan. Feedback to central command will confirm this. If the event turns out to be more extensive or different to that anticipated, then details of the scenario may have to be fed back to central command and the plan worked out there first. Then the chosen course of action will be communicated to the assets in the field and regular reports requested to check that the effects are as anticipated. If new 
situation come to light, then new courses of action may have to be planned for. More complex incidents may require multi-agency cooperation, which will also be managed from central command. When all danger is removed from the situation and the incident is cleaned up, the scenario may be ended.

In the civilian domain, such as ATC, the scenario begins with receipt of a call from an aircraft to request for clearance to enter specified airspace. The mission objectives are overarching for all scenarios, such as the safe and efficient transport of aircraft within and between sectors. There are rules for aircraft separation and set procedures if this separation is compromised. An aircraft may request a descent so that it can land at an airport. The ATCO has to assess the effects and risks, and determine a sequence of actions that will achieve the desired outcome. The exact set of actions will be affected by a number of factors, such as the workload of the ATCO, weather conditions, and number of aircraft and complexity of airspace. The ATCO will, in effect, mentally anticipate the likely outcome of the planned actions for the aircraft in question and those in the near airspace. The chosen course of action will be written onto the flight strip and communicated to the pilot. The rules require a read-back for every instruction given. The ATCO will monitor the progress of the aircraft, to check that the pilot is progressing as planned. If the aircraft does not appear to be making progress, the ATCO will request a situation update from the pilot. The scenario ends when the aircraft leaves the sector being monitored by the ATCO.

Thus it is possible to use this model to explain some of the complexity of different command and control domains.

\section{Conclusions}

The generic process model of command and control developed in the course of the research appears to have some differences to those models considered earlier. The four models presented were Lawson's (1981) control theoretic model, Hollnagel's (1993) control modes model, Rasmussen (1974) and Vicente’s (1999) decision ladder model, and Smalley’s (2003) functional command and control model.

The model in figure five contains all of the information processing activities within Lawson's model (shown in figure one), but with greater fidelity and relevance to 
command and control activities. There is no explicit representation of a 'desired state' in the newer model (see figure four); rather this is expressed in terms of 'required effects' which may be open to change in light of changes in the mission or events in the world. It is also worth noting that the 'desired state' remains static in Lawson's model, which is a weakness of the approach.

Whilst much of the command and control activities are implicitly listed in Hollnagel's model (shown in figure two) under 'goals', 'plans', 'execution' and 'events', the new model makes all of these activities explicit (see figure four). The model does not indicate the effects of temporal change on the command and control activities. The model does however distinguish between the proactive 'command' activities and the reactive 'control' activities. It is probable that in higher tempo situations the command and control system is more likely to be in a reactive mode (i.e., the righthand side of figure five). Conversely, it is probable that in lower tempo situations the command and control system is more likely to be in a proactive mode of operation (i.e., the left-hand side of figure five).

The new activities model in figure five does not attempt to distinguish between knowledge and system states in the way that Rasmussen and Vicente's decision ladder model does. The decision ladder model has the inherent flexibility of shortcuts (which the analyst is required to identify), which can be used to indicate different levels of expertise. This makes the decision ladder model a better explanation of individual behaviour, but less applicable to the description of the activities in a command and control system. The generic decision ladder model could be used to describe any system, but it lacks the fidelity of Smalley's model for command and control. The decision ladder model does not attempt to distinguish between command and control activities, nor proactive and reactive behaviour.

As with Smalley's model (shown in figure four), the new model (see figure five) does distinguish between 'command' activities and 'control' activities, and between 'internal' and 'external' co-ordination. The new model does not attempt to distinguish between 'information processing' and 'decision support' functions, primarily as the purpose of the generic model was to remain independent of technology and allocation of function. As with Smalley's model, the newer model 
also has a high degree to fidelity with regard to the command and control activities. This was seen as a strength of both of the models. Whereas Smalley's model was based solely on military command and control the newer model was based on a broader domain base. Both models provide a basis for research investigations into command and control activities.

Given the various models above, the relatively invariant properties of command and control scenarios can be distilled down to a basic descriptive level as a scenario possessing:

- a common overall goal (comprised of different but interacting sub-goals),

- individuals and teams coordinating to reach it, but

- dispersed geographically, and there are

- numerous systems, procedures and technology to support their endeavour (Walker et al., 2006).

Beyond the descriptive level, command and control by definition is a collection of functional parts that together form a functioning whole. Command and control is a mixture of people and technology, typically dispersed geographically. It is a purposeful intelligently adaptive endeavour representing progress towards a defined outcome. Intelligent adaptation requires responses to externally generated input events within a finite and specified period (Young, 1982). In possessing these attributes, command and control can be characterised with reference to, and understood from the following modelling perspectives, as:

- An (open) system of interacting parts,

- A socio technical system of human and non-human agents and artefacts,

- A distributed system,

- A real time system, and

- $\quad$ an intelligent system.

There are numerous modelling challenges underlying command and control and the attributes above. Foremost is that the, "real world is made from open, interacting 
systems, behaving chaotically” (Hitchins, 2000), and in the case of human actors, non-linearly. Complex systems like command and control scenarios also possess various real-time properties that cannot be considered 'designed' as such, they sometimes merely 'happen’ (Hitchins, 2000). Therefore the notion of a commander representing something akin to the conductor of an orchestra is in some cases entirely false (Hitchins, 2000). Also, unlike clearly linear systems, the possibility exists for there to be no clear boundaries between certain system elements, as well as no beginning and no end, given that goals are more or less externally adaptive. Within this, the concept of situational awareness arises as a "necessary component in achieving decision superiority” (p. 28), and one of the key emergent properties from any command and control scenario (DoD, 1999). Added to the previous challenges, in virtually anything other than the physical sciences a theory such as situational awareness is more akin to, "a general principle or a collection of interrelated general principles that is put forward as an explanation of a set of known facts and empirical findings” (Reber, 1995, p. 793). Thus the modelling of a generic command and control system as an entity is very challenging; as this is a complex social-technical environment that aims to promulgate a shared situational understanding across dispersed geographical locations, using various technical and communications media.

By conducting observations across several domains, the aim of this work has been to develop a generic framework for command and control. In order to progress this into a coherent theory, the next phase of the work is to explore how the various domains perform operations within each heading and to ask how the removal or disruption of activity under a heading will impair performance within a given domain. An approach to this would be to employ the WESTT (workload, error, situational awareness, time and teamwork) modelling tool (Houghton et al., this volume).

\section{REFERENCES}

Bar Yam, Y. (1997). Dynamics of complex systems. Jackson, TN: Perseus

Builder, C. H., Bankes, S. C. \& Nordin, R. (1999). Command concepts: A theory derived from the practice of command and control. Santa Monica, CA: Rand.

DoD (1999). Realizing the potential of C4I: Fundamental Challenges. Washington, DC: National Academy Press. 
Hollnagel, E. (1993). Human reliability analysis: Context and control. London: Academic Press.

Houghton, R. J., Baber, C., Cowton, M., \& Stanton, N. A. (2006) WESTT (Workload, Error, Situational Awareness, Time and Teamwork): An analytical prototyping system for command and control. Cognition, Technology and Work.

Houghton, R.J., Baber, C., McMaster, R., Stanton, N.A., Salmon, P., Stewart, R.J., \&Walker, G. (2006). Command and control in emergency services operations: A social network analysis. Ergonomics, 49 (12-13), 1204 - 1225.

Hoyle, G. (2001) FCTT WP 19, 13 \&15 - Support Facilities. Report No. SEA/00/TR/2296 - CHS575/FCTT/880028 (Restricted). Bristol: SEA.

Hitchins, D. K. (2000) http://www.hitchins.net/CandC.html

Lawson, J. S. (1981) Command and control as a process. IEEE Control Systems Magazine, March, 86-93.

Naikar N, \& Pearce B (2004). Analysing activity for future systems. Defence Science and Technology Organisation. Unpublished report.

McMaster, R., Baber, C., \& Houghton, R. J. (2005). Investigating alternative network structures for operational command and control. $10^{\text {th }}$ International Command and Control Research and Technology Symposium, McLean Virignia, USA, June 2005.

Rasmussen, J. (1974). The human data processor as a system component: Bits and pieces of a model (Report No. Risø-M-1722). Roskilde, Denmark: Danish Atomic Energy Commission.

Reber, A. S. (1995) Dictionary of Psychology. London: Penguin

Smalley, J. (2003) Cognitive factors in the analysis, design and assessment of command and control systems. In: E. Hollnagel (ed) Handbook of Cognitive Task Design. Mahwah, New Jersey: Lawrence Erlbaum Associates (223-253).

Stanton, N. A., Stewart, R. J., Harris, D., Houghton, R. J., Baber, C., McMaster, R., Salmon, P., Hoyle, G., Walker, G., Young, M. S., Linsell, M., Dymott, R. \& Green, D. (2006). Distributed situational awareness in dynamic systems: theoretical development and application of an ergonomics methodology. Ergonomics, 49 (12-13), 1288- 1311.

Stewart, R. J. et al (2007) Cognition, Technology and Work.

Vicente, K. J. (1999). Cognitive work analysis: Toward safe, productive, and healthy computer-based work. Mahwah, NJ: Lawrence Erlbaum Associates

Wainwright, J. \& Mulligan M. (Eds) (2004). Environmental modelling: Finding simplicity in complexity. London: John Wiley \& Sons Ltd. 
Walker, G. H.; Gibson, H.; Stanton, N. A.; Baber, C.; Salmon, P. \& green, D. (2006) EAST (Event Analysis of Systemic Teamwork): A novel integration of ergonomics methods to analyse C4i activity, Ergonomics, 49 (12-13), 1345- 1369.

Young, S. J. (1982). Real time languages: Design and Development. Chichester: Ellis Horwood. 


\section{LIST OF FIGURES}

Figure 1. An adapted version of Lawson's model of the command and control process. From: Lawson, J. S. (1981) Command and control as a process. IEEE Control Systems Magazine, March, 86-93.

Figure 2. Hollnagel's contextual control model. From: Hollnagel, E. (1993). Human reliability analysis: Context and control. London: Academic Press.

Figure 3. Rasmussen and Vicente's decision ladder model. From: Rasmussen, J. (1974). The human data processor as a system component: Bits and pieces of a model (Report No. Risø-M-1722). Roskilde, Denmark: Danish Atomic Energy Commission.

Figure 4. Smalley's functional command and control model. From: Smalley, J. (2003) Cognitive factors in the analysis, design and assessment of command and control systems. In: E. Hollnagel (ed) Handbook of Cognitive Task Design. Mahwah, New Jersey: Lawrence Erlbaum Associates (223-253).

Figure 5. Generic process model of command and control. 


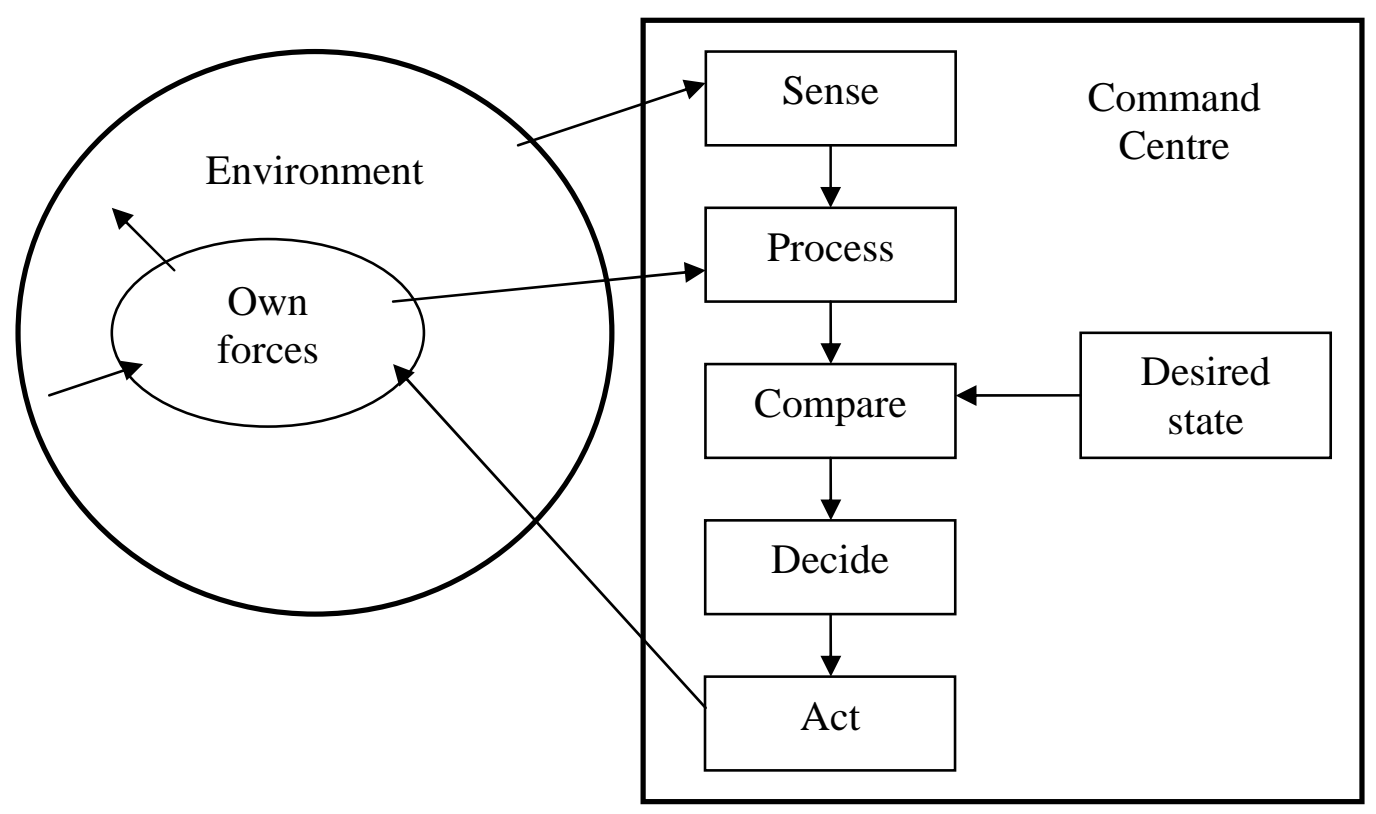

Figure 1. An adapted version of Lawson's model of the command and control process. From: Lawson, J. S. (1981) Command and control as a process. IEEE Control Systems Magazine, March, 86-93. 


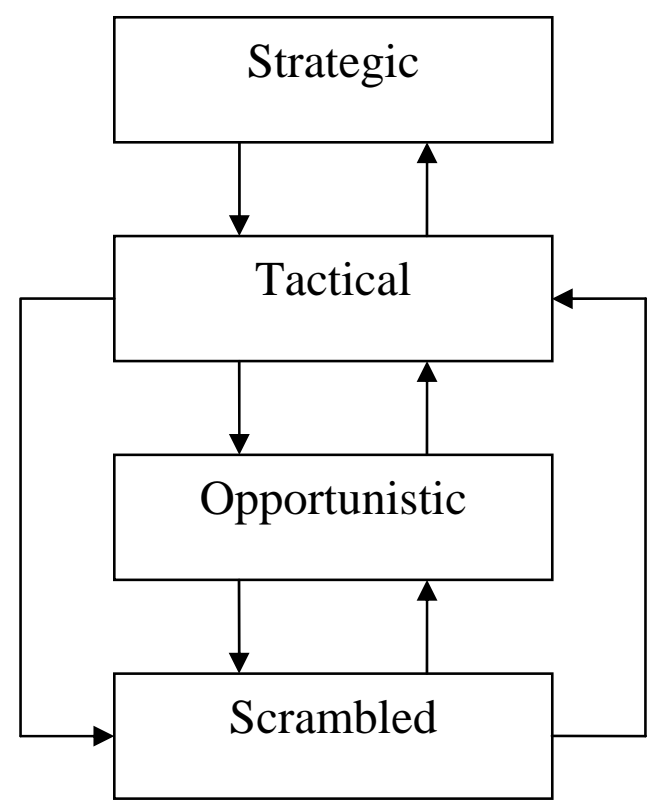

Figure 2. Hollnagel's contextual control model. From: Hollnagel, E. (1993). Human reliability analysis: Context and control. London: Academic Press. 


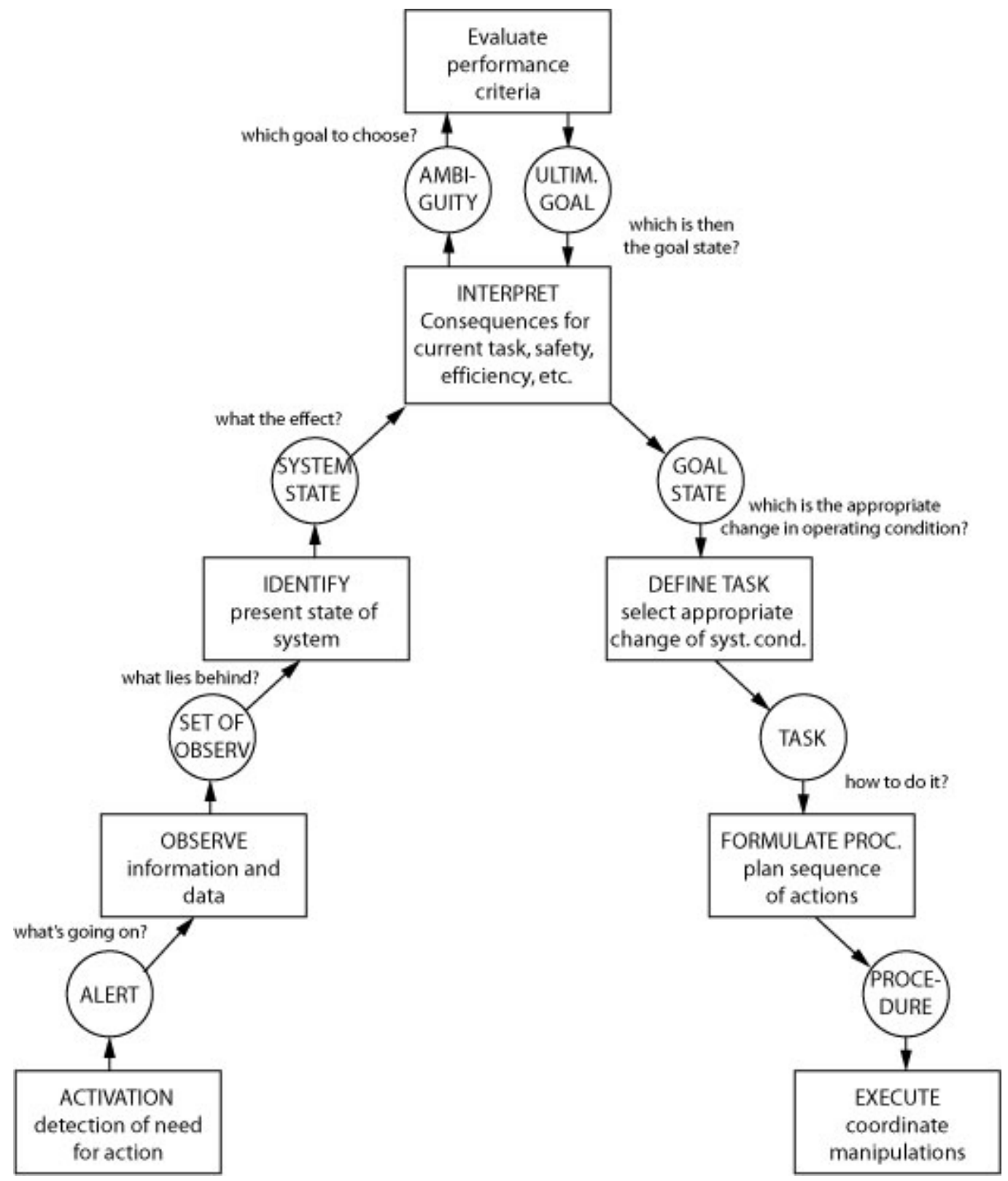

Figure 3. Rasmussen and Vicente’s decision ladder model. From: Rasmussen, J. (1974). The human data processor as a system component: Bits and pieces of a model (Report No. Risø-M-1722). Roskilde, Denmark: Danish Atomic Energy Commission. 


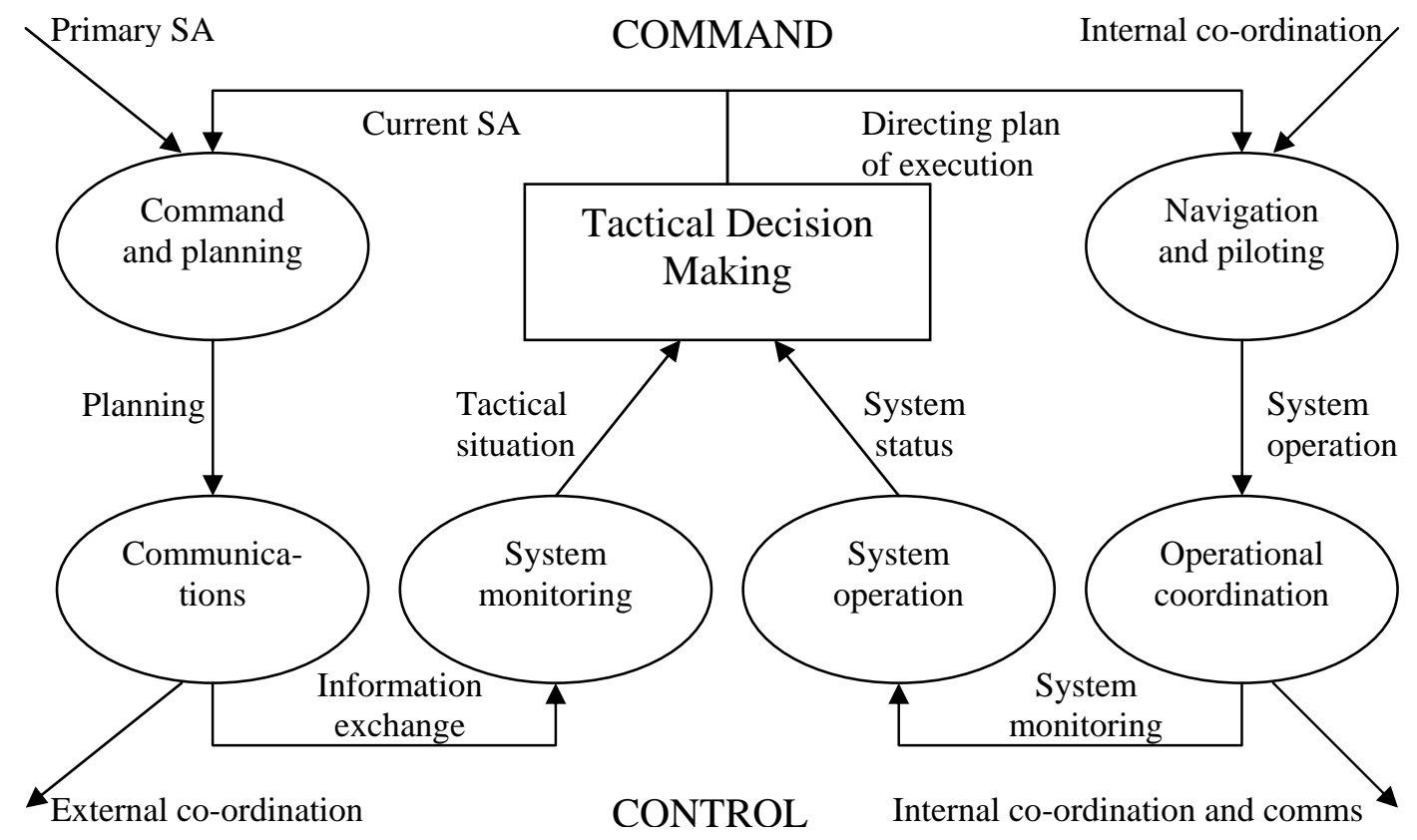

Figure 4. Smalley's functional command and control model. From: Smalley, J. (2003) Cognitive factors in the analysis, design and assessment of command and control systems. In: E. Hollnagel (ed) Handbook of Cognitive Task Design. Mahwah, New Jersey: Lawrence Erlbaum Associates (223-253). 


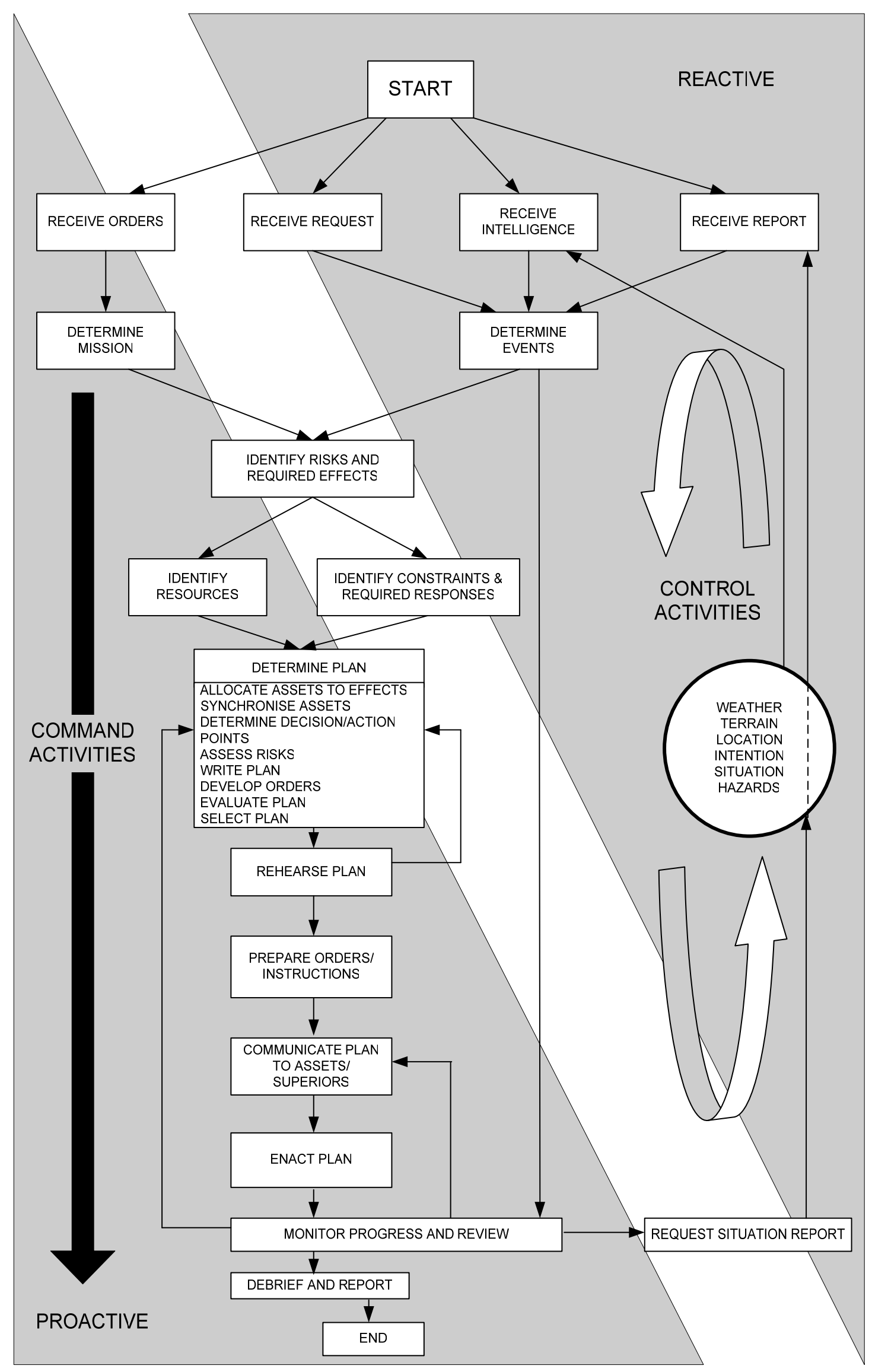

Figure 5. Generic process model of command and control. 


\section{LIST OF TABLES}

Table 1. Taxonomy of command and control activities

Table 2. The 'receive' activities taxonomy

Table 3. The 'planning' activities taxonomy

Table 4. The 'rehearsal' activities taxonomy

Table 5. The 'communicate’ activities taxonomy

Table 6. The 'request' activities taxonomy

Table 7. The 'monitor' activities taxonomy

Table 8. The 'review' activities taxonomy 
Table 1. Taxonomy of command and control activities

\begin{tabular}{|l|l|l|}
\hline Category & Table No. & Definition of activities \\
\hline Receive & 2 & Receipt of data or information, a request or an order \\
\hline Plan & 3 & Planning activities and planning decisions \\
\hline Rehearse & 4 & Rehearsal of plan prior to action \\
\hline Communicate & 5 & Transfer of verbal, written or pictorial information \\
\hline Request & 6 & Request for data and information or assistance \\
\hline Monitor & 7 & $\begin{array}{l}\text { Monitoring and recording of effects of plan } \\
\text { implementation }\end{array}$ \\
\hline Review & 8 & Reviewing the effectiveness of plans or actions \\
\hline
\end{tabular}


Table 2. The 'receive' activities taxonomy

\begin{tabular}{|c|c|c|c|c|c|c|c|c|}
\hline Domains & $\begin{array}{l}\text { Emerg } \\
\text { Service } \\
\end{array}$ & $\begin{array}{l}\text { ency } \\
\text { s }\end{array}$ & Civilia & Service & & Armec & Servic & \\
\hline $\begin{array}{l}\text { Receive } \\
\text { taxonomy }\end{array}$ & Police & Fire & NATS & NGT & NR & Army & Navy & Air \\
\hline Incoming calls & & & & & & & & \\
\hline Paper message & & & & & & & & \\
\hline Face to face & & & & & & & & \\
\hline Diary of work & & & & & & & & \\
\hline Incoming alarms & & & & & & & & \\
\hline Identity exchange & & & & & & & & \\
\hline Live displays & & & & & & & & \\
\hline $\begin{array}{l}\text { Pre planned/pre- } \\
\text { defined activities }\end{array}$ & & & & & & & & \\
\hline Database & & & & & & & & \\
\hline Handover & & & & & & & & \\
\hline $\begin{array}{l}\text { Procedures/systems } \\
\text { (implicit comms) }\end{array}$ & & & & & & & & \\
\hline
\end{tabular}


Table 3. The 'planning' activities taxonomy

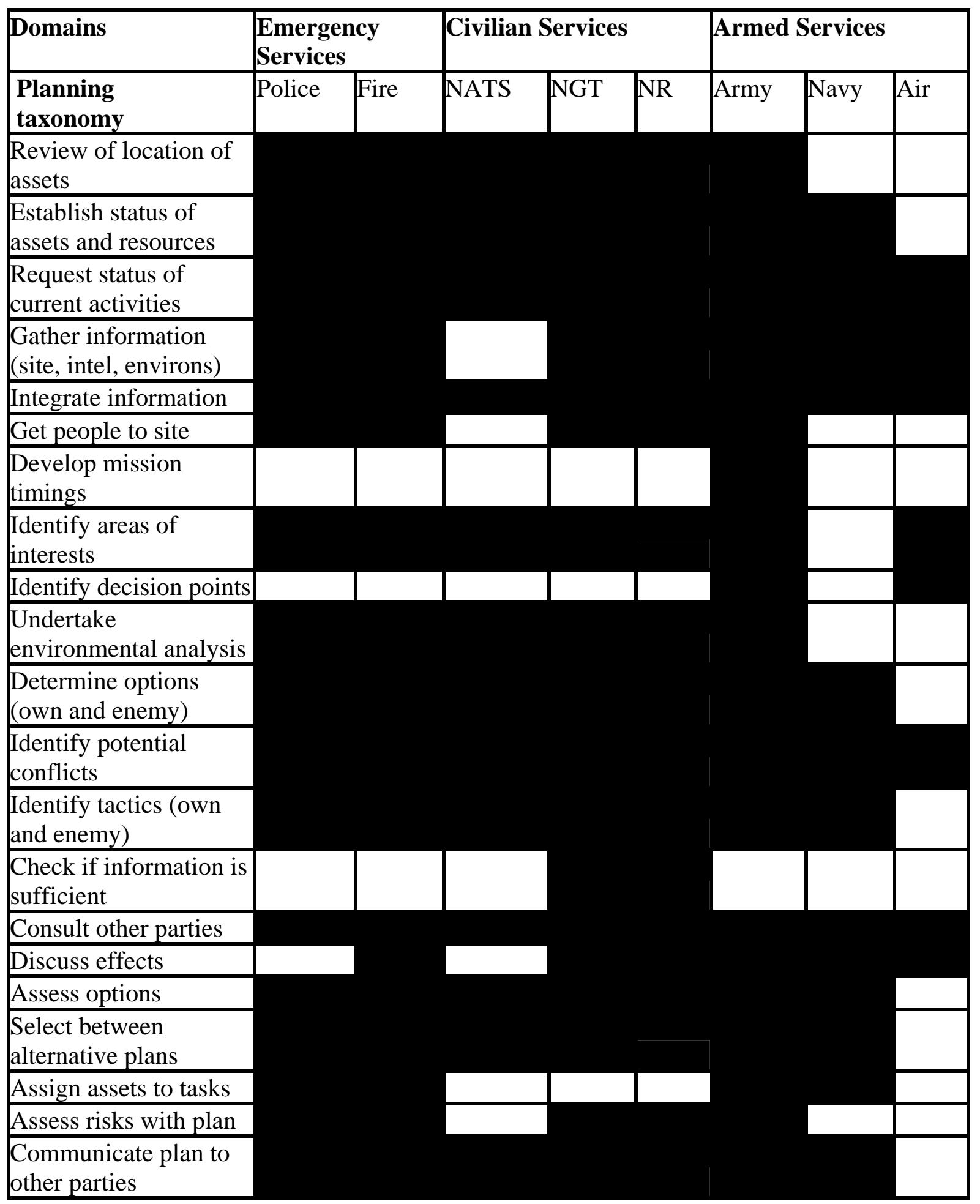


Table 4. The 'rehearsal' activities taxonomy

\begin{tabular}{|l|l|l|l|l|l|l|l|l|}
\hline Domains & \multicolumn{2}{|l|}{$\begin{array}{l}\text { Emergency } \\
\text { Services }\end{array}$} & \multicolumn{3}{|l|}{ Civilian Services } & \multicolumn{3}{|l|}{ Armed Services } \\
\hline $\begin{array}{l}\text { Rehearsal } \\
\text { taxonomy }\end{array}$ & Police & Fire & NATS & NGT & NR & Army & Navy & Air \\
\hline $\begin{array}{l}\text { Discuss plan } \\
\text { verbally }\end{array}$ & & & & & & & \\
\hline $\begin{array}{l}\text { Move assets on } \\
\text { map to rehearse } \\
\text { plan }\end{array}$ & & & & & & & & \\
\hline
\end{tabular}


Table 5. The 'communicate' activities taxonomy

\begin{tabular}{|c|c|c|c|c|c|c|c|c|}
\hline \multirow{2}{*}{\begin{tabular}{|l|} 
Domains \\
$\begin{array}{l}\text { Communicate } \\
\text { taxonomy }\end{array}$
\end{tabular}} & \multicolumn{2}{|c|}{\begin{tabular}{|l} 
Emergency \\
Services
\end{tabular}} & \multicolumn{3}{|c|}{ Civilian Services } & \multicolumn{3}{|c|}{ Armed Services } \\
\hline & Police & Fire & NATS & NGT & NR & Army & Navy & Air \\
\hline \multicolumn{9}{|l|}{ Exchange identities } \\
\hline \multicolumn{9}{|l|}{ Issue instructions/orders } \\
\hline \multicolumn{9}{|l|}{ Read-back instructions } \\
\hline \multicolumn{9}{|l|}{ Confirm read-back } \\
\hline $\begin{array}{l}\text { Record date and time of } \\
\text { instructions }\end{array}$ & & & & & & & & \\
\hline
\end{tabular}


Table 6. The 'request' activities taxonomy

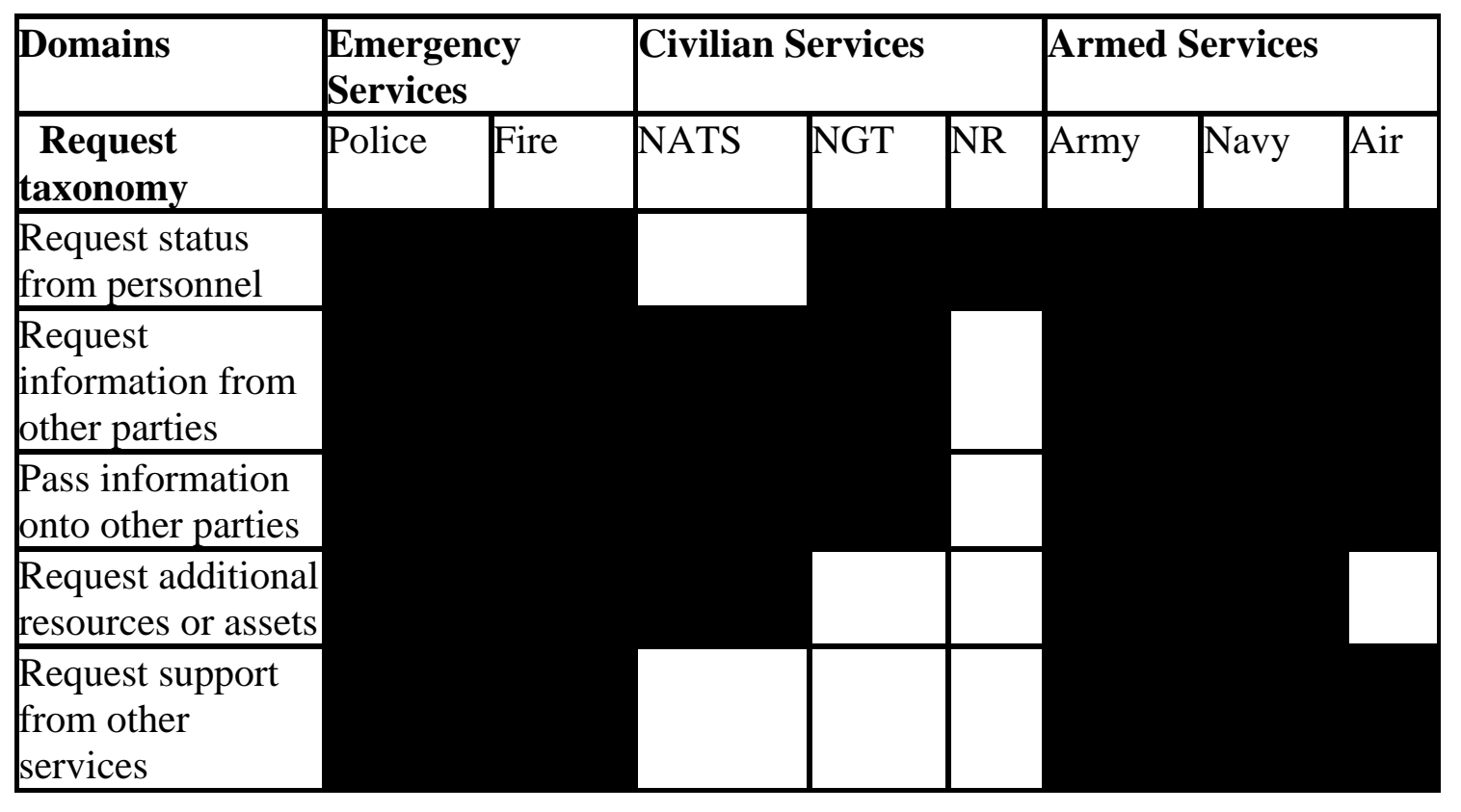


Table 7. The 'monitor' activities taxonomy

\begin{tabular}{|c|c|c|c|c|c|c|c|c|}
\hline \multirow{2}{*}{\begin{tabular}{|l|} 
Domains \\
$\begin{array}{l}\text { Monitor } \\
\text { taxonomy }\end{array}$
\end{tabular}} & \multicolumn{2}{|c|}{$\begin{array}{l}\text { Emergency } \\
\text { Services }\end{array}$} & \multicolumn{3}{|c|}{ Civilian Services } & \multicolumn{3}{|c|}{ Armed Services } \\
\hline & Police & Fire & NATS & NGT & NR & Army & Navy & Air \\
\hline $\begin{array}{l}\text { Track assets } \\
\text { (and enemy) }\end{array}$ & & & & & & & & \\
\hline $\begin{array}{l}\text { Identify } \\
\text { conflicts with } \\
\text { plan }\end{array}$ & & & & & & & & \\
\hline $\begin{array}{l}\text { Allocate } \\
\text { resource and } \\
\text { assets to tasks }\end{array}$ & & & & & & & & \\
\hline $\begin{array}{l}\text { Control } \\
\text { resources and } \\
\text { assets }\end{array}$ & & & & & & & & \\
\hline $\begin{array}{l}\text { Record } \\
\text { changes to } \\
\text { plan }\end{array}$ & & & & & & & & \\
\hline
\end{tabular}


Table 8. The 'review' activities taxonomy

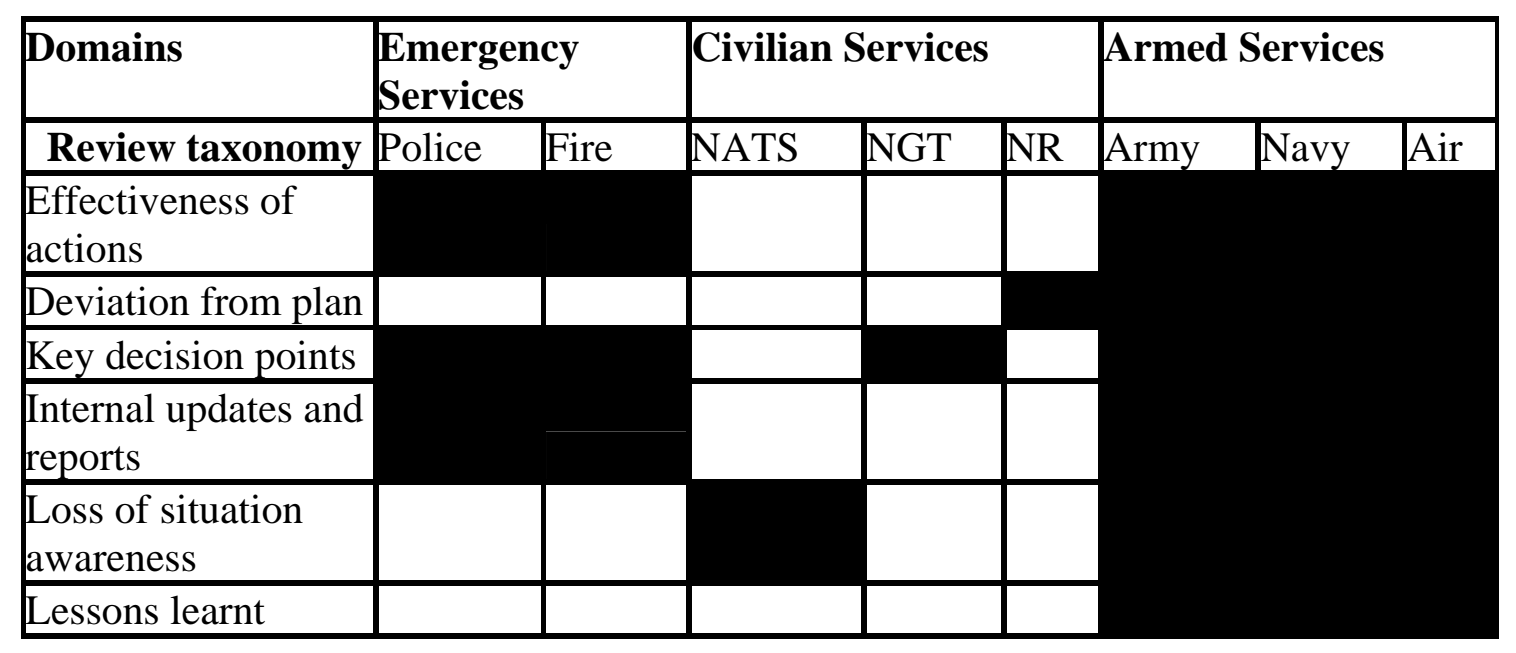

